\title{
SUBNORMALITY VERSUS RESTRICTIONS
}

\author{
FRANCISZEK HUGON SZAFRANIEC \\ Institute of Mathematics, Jagiellonian University \\ Reymont St. 4, 30-059 Kraków, Poland \\ E-mail: Franciszek.Szafraniec@uj.edu.pl
}

Let $S$ be a densely defined operator in a Hilbert space $\mathcal{H}$ having invariant domain, that is, $S \mathcal{D}(S) \subset \mathcal{D}(S)$. Set $\mathcal{D}_{f}:=\{p(S) f: p \in \mathbb{C}[z]\}$ and $\mathcal{H}_{f}:=\operatorname{clo} \mathcal{D}_{f}$. Apparently $S_{f}:=\left.S\right|_{\mathcal{D}_{f}}$ is densely defined in $\mathcal{H}_{f}$.

Question. Is $S$ subnormal if so is $S_{f}$ for any $f \in \mathcal{D}(S)$ ?

\section{References}

[1] F. H. Szafraniec, Subnormality and cyclicity, in: Topological Algebras, Their Applications, and Related Topics, K. Jarosz and A. Sołtysiak (eds.), Banach Center Publ. 67, Inst. Math., Polish Acad. Sci., Warszawa, 2005, 349-356. 